\title{
Adolescent Internalizing, Externalizing, and Social Problems Following Iron Deficiency at 12-18 Months: The Role of Maternal Responsiveness
}

\author{
Jenalee R. Doom (iD \\ University of Michigan \\ Pamela Encina \\ University of Chile
}

\author{
Sheila Gahagan and Patricia L. East \\ University of California, San Diego
}

\author{
Jorge Delva \\ Boston University
}

\author{
Betsy Lozoff \\ University of Michigan
}

\begin{abstract}
This study tested whether maternal responsiveness moderated or mediated pathways from iron deficiency (ID) at 12-18 months to adolescent behavior problems. Participants were part of a large Chilean cohort $(N=933)$. Iron status was assessed at 12 and 18 months. Maternal responsiveness was assessed at 9 months and 5 years. Parents reported their child's symptomology at 5 years, 10 years, and adolescence (11-17 years; $M=14.4)$. Structural equation modeling identified a previously unrecognized pathway by which child externalizing problems and negative maternal responsiveness at 5 years mediated associations between ID at 12 18 months and adolescent internalizing, externalizing, and social problems. Positive maternal responsiveness in infancy did not buffer those with ID anemia from developing 5-year internalizing problems.
\end{abstract}

Iron deficiency (ID) is one of the most common micronutrient deficiencies in the world, affecting children and adults in both industrialized and nonindustrialized countries (Kassebaum et al., 2014). ID in infancy and early childhood has been associated with increased internalizing, externalizing, and social problems at different points in the lifespan, ranging from infancy to young adulthood (Doom et al., 2018; Lozoff, Jimenez, Hagen, Mollen, \& Wolf, 2000; Lozoff et al., 2013). Even after treatment for ID during infancy and early childhood, longterm effects have been observed (Lozoff, Beard, et al., 2006; Lozoff et al., 2000, 2013). The longitudinal pathways by which ID in infancy and early childhood might affect internalizing, externalizing, and social problems into adolescence are unclear and likely include both neurobiological and psychosocial alterations, such as changes in

We thank the families who have participated and continue to participate in this research. Funding from F32HD088029 (PI: Jenalee R. Doom), R01HD14122 (PI: Betsy Lozoff), R01HD33487 (PI: Betsy Lozoff and Sheila Gahagan), R01DA021181 (PI: Jorge Delva), R01HL088530 (PI: Sheila Gahagan), and T32DK071212 to Jenalee R. Doom. The sponsors had no role in the study design, the collection, analysis, or interpretation of data, the writing of the report, or the decision to submit the manuscript for publication.

Correspondence concerning this article should be addressed to Jenalee R. Doom, 300 N. Ingalls St. 10th Floor, Ann Arbor, MI 48109. Electronic mail may be sent to jrdoom@umich.edu. neurotransmitter systems or in parent-child relationships. Social factors may play an important role in moderating or mediating the effects of early ID, but this possibility has seldom been tested. This study investigated the role of maternal responsiveness in potentially moderating or, separately, mediating pathways from ID in infancy and early childhood to adolescent socioemotional and behavioral problems. Understanding how early ID affects developmental pathways, and particularly the role that parents play in these pathways, may provide targets for interventions to improve functioning across the lifespan for individuals who experience early ID.

\section{Effects of ID on Socioemotional Functioning and Behavior}

ID in infancy and early childhood, a period of rapid neurodevelopment, is associated with subsequent poorer cognitive functioning and attention, behavioral disturbances, social alterations, and

(C) 2019 Society for Research in Child Development All rights reserved. 0009-3920/2020/9103-0027 DOI: $10.1111 /$ cdev.13266 
emotional difficulties including increased problems with depression and anxiety (Doom et al., 2018; Lozoff, Beard, et al., 2006; Lozoff et al., 2000, 2013). Effects are often long lasting, with impairments in some domains persisting into adulthood. A study of Costa Rican young adults who had chronic ID in infancy (i.e., were treated during the second year of life), reported more negative emotions and greater dissociation and detachment at 25 years than those who were iron sufficient in infancy (Lozoff et al., 2013). Those with ID in infancy in the Costa Rica study also had more parent- and teacher-reported social and attention problems and greater anxiety and depressive symptoms at ages 11-14 years (Lozoff et al., 2000). Iron treatment or supplementation typically leads to the correction or prevention of ID anemia (IDA) in infancy (Lozoff et al., 1987; Walter, Pino, Pizarro, \& Lozoff, 1998). However, iron therapy does not always reverse the cognitive, social, and behavioral effects of early ID, and even with normal iron status later in development, these effects may remain (Georgieff, 2011; Lozoff, Beard, et al., 2006). These findings suggest that infancy and early childhood are periods that are especially sensitive to the effects of ID on brain development and subsequent behavior.

\section{Mechanisms for Effects of ID on Behavior}

Through extensive work in animal models, we know that ID is associated with disruptions in myelination, glial and neuronal development, neurometabolism, and function of neurotransmitters, including monoamines (Beard \& Connor, 2003; Georgieff, 2011; Lozoff, 2011; Lozoff, Beard, et al., 2006; Unger et al., 2007). Brain processes that are rapidly unfolding during the neonatal and infant periods, when there is a higher likelihood for ID due to the demands of rapid growth, include monoamine neurotransmission, neurometabolism, and myelination (Doom \& Georgieff, 2014). Alterations in these basic neural processes early in life may disrupt the development of cognitive, social, emotional, sensory, and motor abilities, which in turn impede the subsequent development of skills and have long-term developmental consequences (Hensch, 2004). Alterations in neurotransmitter systems, neurometabolism, and myelination early in life have been associated with disruptions in affect, processing speed, and learning and memory (Doom \& Georgieff, 2014; Lozoff et al., 2000, 1998; Siddappa et al., 2004). ID during the early postnatal period is also associated with problems with attention and higher-order processing, which is consistent with the rapid development of the striatum, hippocampus, and prefrontal cortex during this period (Georgieff, 2011; Lozoff et al., 2000; Lukowski et al., 2010). In addition, ID likely disrupts normal development of neural networks that are rapidly developing during the time of the deficiency and also likely disrupts connections between these networks and regions of the brain with more protracted development, such as the prefrontal cortex (Doom \& Georgieff, 2014). This is a potential reason why ID has been associated with a diverse array of disruptions across several domains of functioning, including social, behavioral, neurocognitive, and emotional problems.

Behavioral processes are also proposed to mediate effects from ID in infancy and early childhood to later social, emotional, and behavioral problems. Examples include the functional isolation hypothesis and other alterations in parenting. The functional isolation hypothesis suggests that infants with ID are more wary and hesitant, less expressive, less active, and engage less with caregivers (Lozoff et al., 2000, 1998), which leads caregivers to provide the infant with less developmentally supportive interactions (East et al., 2017). Over time, less supportive interactions can contribute to less optimal brain development and greater behavior problems later. Initial support for this hypothesis demonstrated that ID in infancy and early childhood was associated with dull affect and greater social reticence in children at age 5, which was associated with low maternal responsiveness and stimulation. These maternal behaviors were associated with peer rejection at 10 years, which predicted more deviant friends, substance use, and delinquency in adolescence (East et al., 2017).

As described in Lozoff and colleagues' conceptual model of the mechanisms between early ID and poorer developmental outcomes (1998), parentchild interaction and parenting behaviors have been hypothesized as a mediator between early ID and later development. Specifically, they hypothesized that neurobiological mechanisms lead to disruptions in child behaviors, which then evoke less positive parenting behaviors, including low responsiveness and low social stimulation. These changes in parenting behavior may limit opportunities for positive interactions that support child development, which may in turn exacerbate child behavioral and social problems.

It is also possible that early behavioral and emotional problems resulting from ID in infancy could elicit less warm and responsive parenting, which could exacerbate internalizing, externalizing, and 
social problems across childhood and adolescence. This type of parenting is different than that described in the functional isolation hypothesis, in which parents stimulate their child less because the child is less engaged and interactive. For example, if children have behavior problems, their parents might respond in a harsher and less sensitive manner due to the child's negative behaviors rather than interacting less with the child.

Another possibility is that the quality of parenting may moderate the effects of ID on children's behavior, potentially buffering children who are iron deficient in infancy and early childhood from developing emotion and behavior problems. Sensitive, responsive caregiving early in life is associated with fewer behavior problems later in development (Mills-Koonce et al., 2016; Sulik et al., 2015). This moderating role of parenting has not been tested in the context of early ID. That is, responsive caregiving could reduce behavior problems for children who experienced ID in infancy and early childhood. A similar moderating effect would be evident by ID limiting the effectiveness of responsive caregiving at lowering behavior problems.

\section{Current Study}

To our knowledge, previous studies have not addressed whether maternal responsiveness may moderate or mediate the association between ID in infancy and early childhood and internalizing, externalizing, and social problems in adolescence. Thus, this study was designed to fill an important gap in understanding: (a) whether negative maternal responsiveness is a mechanism by which ID contributes to children's subsequent behavior problems, and (b) whether positive maternal responsiveness buffers the negative effects of ID on children's behavior. Analyses were conducted using a large $(n=933)$, well-characterized sample with prospective measurement of children's iron status and behavior starting in infancy. We hypothesized that ID at $12-18$ months would be associated with children's internalizing, externalizing, and social problems at 5 years, which would relate to more negative maternal responsiveness at 5 years, which would relate to children's internalizing, externalizing, and social problems at age 10 and in adolescence. We predicted that with increasing severity of ID (from iron sufficiency to ID without anemia to ID with anemia, the most severe form; Cook \& Finch, 1979), there would be greater behavior problems, consistent with previous research (Doom et al., 2018). We also hypothesized that positive maternal responsiveness during the child's infancy and age 5 years would buffer the effects of more severe ID at $12-18$ months on behavior problems in adolescence.

\section{Method \\ The Infancy Study}

This study uses data from a large longitudinal cohort of Chilean infants who participated in a randomized IDA preventive trial, some of whom participated in additional study components (referred to as Study 2). Infants were originally enrolled from 1991-1996 at clinics in four working-class communities in Santiago, Chile. Inclusion criteria consisted of birth weight $\geq 3.0 \mathrm{~kg}$, singleton term birth, vaginal delivery, stable caregiver, and residence in the communities. Exclusion criteria included major congenital anomaly, birth complications, phototherapy, hospitalization longer than 5 days, illness, iron therapy, another infant $<12$ months of age in the household, day care for the infant, a caregiver who was illiterate or psychotic, and, until 1994, exclusive breast feeding at 6 months. At the time of enrollment, generalized undernutrition had been nearly eradicated in Chile, so infants were well nourished. Infants in this sample weighed, on average, $3.55 \mathrm{~kg}$ at birth $(S D=0.37 \mathrm{~kg})$ and $10.03 \mathrm{~kg}$ at 12 months $(S D=1.08 \mathrm{~kg})$. Enrollment procedures were the same for all participants, participants were generally healthy, and none were referred by clinics because of concerns.

All infants had a capillary hemoglobin $(\mathrm{Hb})$ screening at 6 months. Infants with screening $\mathrm{Hb} \leq 103 \mathrm{~g} / \mathrm{L}$ received a venipuncture to test iron status. Infants with IDA at 6 months (venous $\mathrm{Hb} \leq 100 \mathrm{~g} / \mathrm{L}$ and 2 of 3 abnormal measures as detailed below) were excluded from the preventive trial and invited to join Study 2 along with the next nonanemic infant (venous $\mathrm{Hb} \geq 115 \mathrm{~g} / \mathrm{L}$ ). All infants in Study 2 received medicinal iron regardless of iron status. More information about Study 2 is described elsewhere (Roncagliolo, Garrido, Walter, Peirano, \& Lozoff, 1998). Infants not enrolled in Study 2 at 6 months were randomized in the double-blind preventive trial into high-iron, low-iron, or no-added-iron groups from ages 6 to 12 months (see flow chart in Figure S1). A total of 1,657 infants completed the preventive trial. Iron supplementation in the preventive trial significantly reduced the development of ID with and without anemia at 12 months and improved social behavior in infancy and at 10 years of age (Lozoff et al., 2003; Lozoff, 
Castillo, Clark, Smith, \& Sturza, 2014; Lozoff, Kaciroti, \& Walter, 2006). More details on study design and preventive trial results are described elsewhere (Lozoff et al., 2014). Supplementation group and receiving medicinal iron were considered as covariates. Infants were followed at ages 5 years, 10 years, and in adolescence. The current sample included 933 participants whose mothers provided data on their child's internalizing, externalizing, and social problems in adolescence (ages 11.817.8 years; $M=14.4, S D=1.5$ ). The infancy study and subsequent follow-ups were approved by the appropriate institutional review boards and were consistent with ethical standards set by the Declaration of Helsinki.

\section{Child Iron Status at 12 and 18 Months}

When children were 12 months, a venous blood sample was collected from all participants to document iron status based on $\mathrm{Hb}$, mean corpuscular volume $(\mathrm{MCV})$, free erythrocyte protoporphyrin (FEP), and serum ferritin. At 18 months, children in the low-iron and no-added-iron randomized groups from the preventive trial and those in Study 2 had repeat testing by venipuncture. A small number of children in the high-iron group who also participated in Study 2 also received a venipuncture ( $n=26 ; 7.4 \%$ of the high-iron group). For those who were not selected for the 18-month venipuncture $(54.8 \%$ of participants), blood status was imputed using multiple imputation techniques (Rubin, 1987) with IVEWARE software within SAS (Raghunathan, Solenberger, \& van Hoewyk, 2000) using available demographic, anthropometric, environmental, and iron status data in infancy and early childhood (Newman, 2003). The best predictor of 18 -month iron status in this sample was 12-month iron status (Lozoff, Kaciroti, et al., 2006). Iron supplementation group (no-added-iron, low-iron, highiron) and 6-month $\mathrm{Hb}$ levels were also significant predictors of iron status at 18 months, so these variables were included in the imputation of iron status at 18 months (for more information on iron status imputation, see Lozoff, Kaciroti, et al., 2006; for follow-up analyses testing analyses with and without imputed iron status data, see Supporting Information section 7.1).

Anemia at 12 and 18 months was defined as $\mathrm{Hb}<110 \mathrm{~g} / \mathrm{L}$. ID was defined as 2 of 3 iron measures in the abnormal range at either time point: MCV $<70 \mathrm{fL}, \mathrm{FEP}>100 \mu \mathrm{g} / \mathrm{dl}$ red blood cells, and ferritin $<12 \mu \mathrm{g} / \mathrm{L}$ (Oski, 1993). Infants with IDA, defined as anemia + ID, at either 12 or 18 months were treated with medicinal iron. A total of 256 participants in this study received medicinal iron. Using each individual's poorest iron status at 12 or 18 months, we classified iron status as IDA, ID without anemia, or iron sufficient (i.e., not having IDA or ID without anemia at both 12 and 18 months). Based on the physiologic progression of ID (Cook \& Finch, 1979), severity of ID at 12 and 18 months was coded as $1=$ iron sufficient at both 12 and 18 months, 2 = ID without anemia at either 12 or 18 months, and $3=$ IDA at either 12 or 18 months (crosstabs of 12-month vs. 18-month iron status in Table S1).

\section{Maternal Responsiveness}

\section{Infancy (9 Months)}

The Home Observation for Measurement of the Environment (HOME) Inventory for ages 0-3 years was conducted by a trained psychologist in the family's home when infants were about 9 months old (Caldwell \& Bradley, 1984). Although the scale measures multiple aspects of the quality of the environment for supporting child development, the subscales specific to the parent (generally the mother) were used for this study. Two scales, parental involvement with the child (6 items) and emotional and verbal responsivity (11 items), were used. Higher scores on these scales reflected more positive and consistent maternal responsiveness. Parental involvement with the child included the following items: (a) parent keeps child in visual range, looks at often; (b) parent talks to child while doing housework; (c) parent consciously encourages developmental advance; (d) parent invests maturing toys with value via personal attention; (e) parent structures child's play periods; (f) parent provides toys that challenge child to develop new skills. Emotional and verbal responsivity included the following items: (a) parent spontaneously vocalized to child twice; (b) parent responds verbally to child's verbalizations; (c) parent tells child name of object or person during visit; (d) parent's speech is distinct and audible; (e) parent initiates verbal exchanges with visitor; (f) parent converses freely and easily; (g) parent permits child to engage in "messy" play; (h) parent spontaneously praises child at least twice; (i) parent's voice conveys positive feelings toward the child; ( $j$ ) parent caresses or kisses child at least once; (k) parent responds positively to praise of child offered by visitor. The interviewer endorsed each of the items observed during the home visit, which were added to create a sum for 
the subscale. These scales were standardized and the mean was used.

\section{Age 5}

Maternal responsiveness, including mothers' responsiveness, warmth and affection, and social stimulation to the child, was assessed at 5 years via interview by a trained psychologist in the lab using items from the HOME-Early Childhood version (Bradley, Corwyn, \& Whiteside-Mansell, 1996). The HOME-EC is a well-validated instrument that has shown high sensitivity to variations in family life, with validation in Latin American countries (Bradley et al., 1996). This measure also shows good equivalence between in-home observation and inperson interview ratings (Han, Leventhal, \& Linver, 2004). A previous study using this sample conducted a principal components analysis on 13 items that addressed maternal behavior (East et al., 2017). Three factors were identified: mothers' responsivity (two items), warmth and affection (three items), and social stimulation (eight items). Responsivity included the following items: (a) mother is responsive to child's speech; (b) mother is responsive to child's requests. Warmth and affection included the following items: (a) mother caresses, kisses or cuddles child during visit; (b) parent holds child close 10-15 min per day; (c) parent praises child's qualities twice during visit. Social stimulation included the following variables: (a) child is encouraged to learn the alphabet; (b) parent teaches child simple verbal manners; (c) parent encourages child to talk and takes time to listen; (d) child is encouraged to learn colors; (e) child is encouraged to learn patterned speech; (f) child is encouraged to learn spatial relations; $(\mathrm{g})$ child is encouraged to learn numbers; (h) child is encouraged to learn to read a few words. High scores on these items indicate frequent and consistent responsiveness, high warmth and affection, and frequent and positive social stimulation. These factors were used as a latent variable for maternal responsiveness.

\section{Child Internalizing, Externalizing, and Social Problems}

\section{Behavior Problems at Age 5}

A follow-up at approximately 51/2 years (range: 5.5-6.0, $M=5.5, S D=0.04$ ), included children in the high- or no-added iron groups from the preventive trial and those in Study 2. Due to budgetary constraints, the low-iron supplementation group was not assessed at age 5, except for 17 children who received medicinal iron as part of Study 2 (beginning at age 10 years, the low-iron group was included in all waves of recruitment). Participants who completed the 5-year assessment had higher socioeconomic status (SES), were more intensely breastfed (as indicated by consuming a lower amount of formula/milk per week on average in infancy), and were more likely to have received medicinal iron, compared to those not assessed.

Mothers rated children's behaviors using the Child Adaptive Behavior Inventory (CABI; Miller, 1987), Spanish version. The CABI has been used to measure behavior problems in nonclinical populations and may be more sensitive to behavioral aberrations in these populations (Mattanah, 2001). Subscales demonstrated good internal reliability (average $\alpha=.81$ ) and predictive validity, and have been validated in several samples (Cowan \& Cowan, 1990; Katz \& Gottman, 1993). In addition, this measure shows moderate-to-high correlations with the Child Behavior Checklist (CBCL; Katz \& Gottman, 1993). The CABI consists of 106 items asking about the frequency of certain behaviors of the child with response options ranging from $0=$ never to $4=$ the majority of the time. The following scales were used: (a) antisocial-disobedient or "breaks the rules," surrounds him or herself with children who are bad influences, takes things that do not belong to him or her, punishment does not affect behavior, does not always tell the truth; (b) hostile - gets upset easily, has a temper, argues and fights, deliberately cruel to others, fights with other children; (c) oppositional - acts like he or she knows everything, looks for attention, does not cooperate in situations with groups of adults or children, waits for others to adapt to his or her desires, stubborn, and irritable; (d) socially isolated-does not defend him or herself; difficult to initiate games with peers and to enter the group, other children do not look to play with him or her, isolates him or herself from others, tends to be ignored by other children, plays or works with only one other child or alone; (e) socially rejected-criticized by other children, left behind by other children, allows other children to boss him or her around, does not get along with same-sex peers, not socially approved by other children, makes comments not related to what the group is doing; (f) anxiousnervous and tense, cries a lot, worries a lot, timid regarding many things, gets angry or bothered easily; (g) depressed-seems unhappy and depressed, can very often sit without doing any activity, seems lonely, does not smile or laugh much, very often sad, has a lost expression or does 
not show emotional expressions. Each of these seven scales were transformed into proportion of maximum scaling (POMS) scores. POMS scores were created due to problems with standardizing variables for longitudinal analysis (Moeller, 2015).

\section{Behavior Problems at Age 10}

At approximately 10 years (range: 9.9-10.5, $M=10.0, S D=0.1$, , parents completed a Spanish version of the CBCL/4-18 (Achenbach \& Edelbrock, 1991). The CBCL is a standardized instrument that has been widely used to measure a number of internalizing, externalizing, and social problems. The Spanish version has shown high reliability and concurrent validity (Rubio-Stipec, Bird, Canino, \& Gould, 1990). The following scales were converted to POMS scores and used for composites: anxious/ depressed, social problems, withdrawn, aggressive, and delinquent. We chose to create our own composite variables at 10 years rather than use the CBCL composite variables to better match the 5year variables from the CABI, which does not have the same items as the CBCL.

\section{Behavior Problems At Adolescence}

For the adolescent assessment (11.8-17.8 years, $M=14.4, S D=1.5)$, the revised parent-report Spanish version of the CBCL/6-18 (Achenbach \& Rescorla, 2001) was used to measure behavior problems. In addition to the traditional scales, this version produces Diagnostic and Statistical Manual of Mental Disorders-oriented scales, which were used to create the constructs of interest. Thus, the resulting composites are slightly different from age 10 . The following sum scores for the scales were converted to POMS scores and used in analyses: depressive, anxious, social problems, oppositional defiant, conduct, and aggressive. Similar to the 10year assessment, we chose to create our own composite variables at adolescence rather than use the CBCL composite variables to better match the 5year variables from the CABI. Supporting Information section 1 includes additional information about the behavior problems variables, including correlations with CBCL composites.

\section{Infancy Control Variables}

Several control variables were used in the analyses. To consider SES effects in infancy, SES was measured using a modified Graffar Index (Alvarez, Muzzo, \& Ivanovic, 1985). This measure accounts for the number of people in the home, educational attainment of the head of household, employment status, home ownership, ownership of major material goods (e.g., home appliances, car), housing type and size, running water, and crowding. The HOME in infancy, discussed in detail above, was completed by an in-home interviewer and used as a control variable to account for home support in infancy for child development (Caldwell \& Bradley, 1984). Maternal education in years and maternal age at child's birth were reported by the mother. Stressors in the child's family during infancy were measured by a modified Social Readjustment Rating Scale (Holmes \& Rahe, 1967). Biological sex of the child was coded as 1 =male, 2 =female. Iron supplementation in the preventive trial was dummy coded with the no-added-iron group as the comparison group for the low- and high-iron groups. Receiving medicinal iron as part of the study was coded as $0=$ did not receive or $1=$ received. To control for feeding in infancy, we included the average daily formula/milk consumption between 6 and 12 months in $\mathrm{ml} /$ day. Formula intake was assessed by study staff members who visited homes of all participants weekly from 6 to 12 months. This variable was inversely correlated with all breastfeeding measures, that is, weaning age (if weaned), nursing at 1 year, and age at first bottle. Data on formula/ milk consumption and breastfeeding were obtained from mothers at weekly home visits. Multiple imputation techniques were used to impute values for control and family background variables with missing values (Rubin, 1987) with IVEWARE software within SAS (Raghunathan et al., 2000; see Table 1 for number of participants with data on each variable). To control for the potential effect of initial iron status, 6-month screening $\mathrm{Hb}$ concentration was considered as a covariate. To assess whether response to iron treatment in infancy may have impacted results, change in $\mathrm{Hb}$ was calculated for infants who received iron treatment. Functional response to iron treatment, defined as $\mathrm{Hb}$ increase $\geq 10 \mathrm{~g} / \mathrm{L}$ from assessment 6 months earlier, was coded as response $=1$ or nonresponse $=0$ ( $\mathrm{Hb}$ increase $<10 \mathrm{~g} / \mathrm{L}=0$; Lozoff et al., 1987) and included as a control variable.

\section{Analytic Strategy}

\section{Creating Composite/Latent Variables}

For each age, scales that theoretically map on to internalizing, externalizing, and social problems were identified, particularly because the 5-year 
Table 1

Descriptive Statistics

\begin{tabular}{|c|c|c|c|c|c|}
\hline & $N$ & Min & Max & $M$ or $\%$ & $S D$ \\
\hline \multicolumn{6}{|l|}{ Age at assessment (y) } \\
\hline $5 \mathrm{y}$ & 600 & 5.5 & 6.0 & 5.5 & 0.04 \\
\hline $10 \mathrm{y}$ & 822 & 9.9 & 10.5 & 10.0 & 0.1 \\
\hline Adolescence & 933 & 11.8 & 17.8 & 14.4 & 1.5 \\
\hline Sex (\% female) & 933 & - & - & $48.3 \%$ & - \\
\hline Maternal age at child's birth (y) & 925 & 14.6 & 46.1 & 26.4 & 6.1 \\
\hline Mother's education (y) & 933 & 1 & 17 & 9.5 & 2.7 \\
\hline Graffar (SES) ${ }^{\mathrm{a}}$ & 930 & 11 & 47 & 27.2 & 6.4 \\
\hline HOME score & 929 & 12 & 42 & 30.5 & 4.7 \\
\hline Maternal stress (number) & 912 & 0 & 14 & 4.7 & 2.6 \\
\hline Formula/milk intake (average ml/day) & 864 & 0 & $1,157.3$ & 416.3 & 207.6 \\
\hline \multicolumn{6}{|l|}{ Iron status at $12-18 \mathrm{~m}$} \\
\hline Iron sufficient & 512 & - & - & $54.9 \%$ & - \\
\hline ID w/o anemia & 294 & - & - & $31.5 \%$ & - \\
\hline ID anemia & 127 & - & - & $13.6 \%$ & - \\
\hline \multicolumn{6}{|l|}{ Supplementation group } \\
\hline High iron & 353 & - & - & $40.8 \%$ & - \\
\hline Low iron & 196 & - & - & $22.6 \%$ & - \\
\hline No added iron & 317 & - & - & $36.6 \%$ & - \\
\hline Received medicinal iron in infancy & 256 & - & - & $27.4 \%$ & - \\
\hline $9 \mathrm{~m}$ maternal emotional/verbal responsivity & 569 & 2 & 11 & 8.4 & 1.9 \\
\hline $9 \mathrm{~m}$ maternal involvement with child & 569 & 0 & 6 & 4.3 & 1.4 \\
\hline 5 y maternal responsivity & 594 & 0 & 2 & 1.9 & 0.4 \\
\hline 5 y maternal warmth/affection & 594 & 0 & 3 & 2.3 & 0.9 \\
\hline 5 y maternal social stimulation & 594 & 0 & 8 & 5.5 & 1.7 \\
\hline 5 y anxious & 590 & 6 & 20 & 13.0 & 3.0 \\
\hline 5 y depressive & 590 & 6 & 21 & 9.6 & 2.7 \\
\hline 5 y social isolation & 590 & 7 & 25 & 13.6 & 3.5 \\
\hline 5 y social rejection & 590 & 7 & 25 & 12.1 & 3.0 \\
\hline 5 y antisocial & 590 & 5 & 17 & 9.9 & 2.5 \\
\hline 5 y hostile & 590 & 4 & 15 & 8.5 & 2.3 \\
\hline 5 y oppositional & 590 & 6 & 23 & 13.2 & 3.4 \\
\hline $10 \mathrm{y}$ anxious/depressed & 819 & 50 & 96 & 63.0 & 8.9 \\
\hline 10 y social problems & 819 & 50 & 93 & 61.8 & 9.1 \\
\hline $10 \mathrm{y}$ withdrawn & 819 & 50 & 97 & 62.7 & 9.3 \\
\hline 10 y aggressive & 819 & 50 & 92 & 59.8 & 9.1 \\
\hline $10 \mathrm{y}$ delinquent & 819 & 50 & 84 & 57.0 & 7.4 \\
\hline Adolescent anxious & 933 & 50 & 91 & 62.7 & 8.4 \\
\hline Adolescent depressive & 933 & 50 & 91 & 61.9 & 8.5 \\
\hline Adolescent social problems & 933 & 50 & 93 & 61.9 & 7.7 \\
\hline Adolescent oppositional defiant & 933 & 50 & 80 & 58.1 & 7.1 \\
\hline Adolescent conduct & 933 & 50 & 86 & 56.3 & 6.5 \\
\hline Adolescent aggressive & 933 & 50 & 94 & 59.7 & 8.3 \\
\hline
\end{tabular}

Note. Values are $n(\%)$ for categorical variables and mean $(S D)$ for continuous variables. Iron status and supplementation group Ns indicate the number of participants (and percentage of total participants) in each group. Percentages were calculated for those with nonmissing data on each variable. $\mathrm{y}=$ years; $\mathrm{m}=$ months; $\mathrm{SES}=$ socioeconomic status; HOME = Home Observation for Measurement of the Environment; ID = iron deficiency.

${ }^{\mathrm{a}}$ Mean Graffar in this sample corresponds to middle SES class.

questionnaire differed from the 10-year and adolescent questionnaires. If three or more scales mapped onto the construct, a latent variable was created to index that construct. We chose to create latent variables in these cases to reduce error while measuring the underlying behavioral construct using latent versus composite variables. Given the problems with latent variables constructed from only 
two indicators (Little, Lindenberger, \& Nesselroade, 1999), a three-indicator cutoff was chosen to create latent variables. If only one scale at a particular age mapped onto the construct, it was used alone as an index of that construct. If two scales mapped onto the construct, the mean of the scales was calculated and used to measure that particular construct.

The variable for internalizing problems at 5 years was constructed using the mean of the anxious and depressed scales. The variable for social problems at 5 years was constructed using the mean of the socially isolated and socially rejected scales. The 5year externalizing variable was a latent variable comprised of the antisocial, oppositional, and hostile scales $(\alpha=.74)$. For the 10-year assessment, internalizing behaviors were measured by the anxious/depressed scale. Social problems at 10 years were measured by the mean of the social problems and withdrawn scales. Externalizing problems at 10 years were measured by the mean of the aggressive and delinquent scales. The mean of the standardized depressive and anxious scales was used to measure adolescent internalizing symptoms. The adolescent social problems scale was used as the social problems variable. The oppositional defiant, conduct, and aggressive scales were used as the latent variable of adolescent externalizing symptoms $(\alpha=.91)$.

\section{Structural Equation Modeling}

Three models were tested: Model 1 was a mediation model with severity of ID at 12 and 18 months as the main predictor of direct and indirect pathways to adolescent internalizing, externalizing, and social problems; Model 2 involved a moderation model testing the interaction between severity of ID at 12 and 18 months, and maternal responsiveness at 9 months predicting pathways to adolescent problems; Model 3 was a moderation model testing the interaction between severity of ID at 12 and 18 months, and maternal responsiveness at 5 years predicting pathways to adolescent problem behaviors. (See Supporting Information section 2 for a summary table of the models in the text and the supplement.).

Structural equation models with bootstrapping (10,000 iterations) were conducted using Mplus 7.4 (Muthén \& Muthén, 2010) to test our hypotheses (Figure S2 for model tested and Figure 1 for results). The maximum likelihood estimator and delta parameterization were used. Our main predictor was severity of ID at 12 and 18 months as an ordinal (continuous) variable of severity
$(1=$ iron sufficient, $2=I D$ without anemia, $3=I D A)$. Endogenous variables were internalizing, externalizing, and social problems at ages 5, maternal responsiveness at age 5, and internalizing, externalizing, and social problems at age 10 and in adolescence. In the main analyses, iron status was assessed as an ordinal variable of severity of ID (Models 1-3). In the secondary analyses (Models 4-6; see Supporting Information sections 4-5), threshold effects of severity of ID were conducted by dummycoding iron status into three categories: iron sufficiency, ID without anemia, and ID with anemia.

Severity of ID at 12 and 18 months and all mediators and outcome variables were regressed onto the infancy and early childhood control variables (iron supplementation, age, sex, formula consumption, maternal age, maternal education, SES, receiving medicinal iron, maternal stress, and HOME score). $\mathrm{Hb}$ at 6 months and response to iron treatment were regressed on 12- to 18-month ID and age 5 internalizing, externalizing, and social problems to control for potential effects of initial iron status or treatment response. Age at the adolescent assessment was regressed on the adolescent outcome variables. Covariates that were not associated with internalizing, externalizing, social problems, or maternal responsiveness $(p>.05)$ at any time point were removed from that time point in the model (Little, 2013). Indices of good model fit were examined ( $\mathrm{Hu}$ \& Bentler, 1999; Kline, 2015), in particular the root mean square error of approximation (RMSEA; <.06), standardized root mean square residual (SRMR; $<.08)$, and the comparative fit index (CFI; > .93). Missing data $(0 \%-36.1 \%$; approximately a third of the sample was not assessed at age 5 due to a severe budgetary cut) were handled using the full information maximum likelihood method (Newman, 2003). The INDIRECT command in Mplus was used to test mediation by estimating indirect effects using the delta method standard errors (Muthén, 2011). Internalizing, externalizing, and social problems at each time point were correlated within time. Paths from 5-year internalizing, externalizing, and social problems to 5-year maternal responsiveness were estimated, and paths from 5year maternal responsiveness to 10-year internalizing, externalizing, and social problems were also estimated. Across-time paths from 10-year to adolescent internalizing, externalizing, and social problems were estimated. To test whether the model might differ by child sex, individual paths between ID at 12-18 months and age 5 


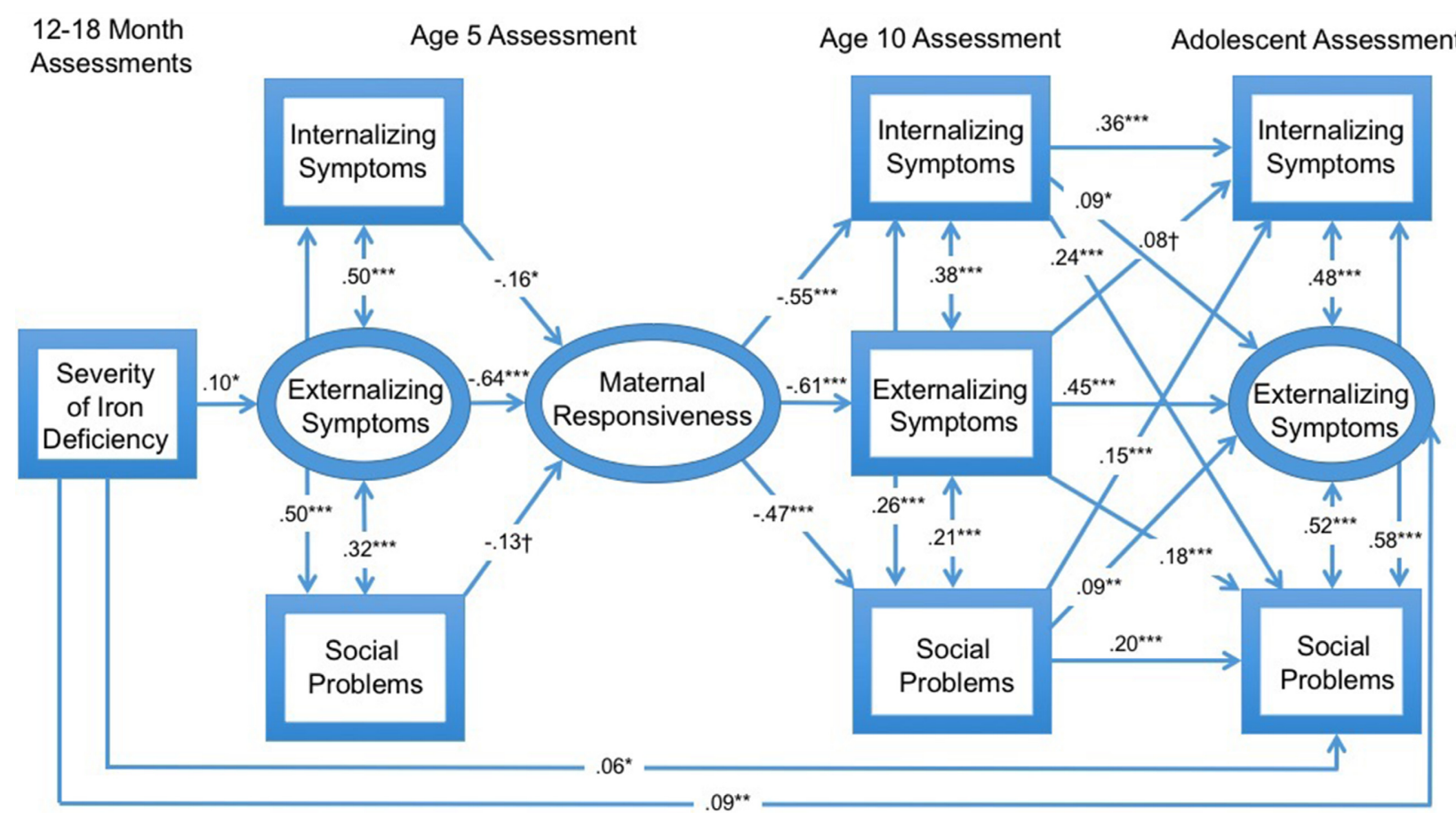

Figure 1. Model 1 results showing standardized estimates $(\beta)$. The standardized estimates indicate the amount of change in $\mathrm{Y}$ per standard deviation unit of $\mathrm{X}$. Only paths with a significance level of $p<.10$ are shown (see Table 3 ). ${ }^{\dagger} p<.10 .{ }^{*} p<.05 .{ }^{* *} p<.01$. *** $p<.001$.

internalizing, externalizing, and social problems were tested for sex differences. If there were no significant path differences by sex, both boys and girls were included in the final model.

Moderation analyses were conducted first with maternal responsiveness at 9 months (Model 2), then at age 5 years (Model 3). Interaction terms were created first between severity of ID at 12 18 months and maternal responsiveness in infancy. The main effects of maternal responsiveness at 9 months and severity of ID at 12-18 months and their interaction were regressed on 5-year internalizing, externalizing, and social problems (see Figure S3 for a diagram of the model that was tested for Models 2 and 3). For these Model 2 analyses, mediation by 5 -year maternal responsiveness was removed from the model, such that paths from ID, maternal responsiveness, and their interaction to adolescent internalizing, externalizing, and social problems were estimated through 5- and 10-year internalizing, externalizing, and social problems. If the interaction term was significantly associated with 5-year internalizing, externalizing, or social problems, indirect effects of the interaction term on adolescent internalizing, externalizing, and social problems were estimated.
The same procedures outlined in the previous paragraph were followed to create interaction terms between severity of ID at 12 and 18 months and 5year maternal responsiveness instead of responsiveness at 9 months. The Model 3 analyses with maternal responsiveness at 5 years as a moderator of ID were conducted using the XWITH command in Mplus to calculate interactions between a latent and observed variable (Maslowsky, Jager, \& Hemken, 2015; Muthén \& Muthén, 2012).

\section{Results \\ Sample Characteristics}

Sample characteristics are summarized in Table 1. Slightly less than half of adolescents were female $(48.3 \%)$, and the majority $(84.3 \%)$ were categorized as low-middle to middle-SES. At 12 and 18 months, over half of participants were iron sufficient $(54.9 \%)$. At 12 or 18 months, $31.5 \%$ had ID without anemia, and $13.6 \%$ had IDA. Iron status groups differed by sex, age at the adolescent assessment, maternal age, SES, formula consumption, iron supplementation group, and receipt of medicinal iron, ps $<.05$ (see Table S2). 
Table 2

Correlation Matrix of Study Variables

\begin{tabular}{|c|c|c|c|c|c|c|c|c|c|c|c|}
\hline Variable & 1 & 2 & 3 & 4 & 5 & 6 & 7 & 8 & 9 & 10 & 11 \\
\hline 1. $12-18 \mathrm{~m}$ ID severity & - & & & & & & & & & & \\
\hline 2. $9 \mathrm{~m}$ mat responsive & $-.09 * *$ & - & & & & & & & & & \\
\hline 3. $5 \mathrm{y}$ internalizing & .03 & $-.07^{*}$ & - & & & & & & & & \\
\hline 4. 5 y externalizing & $.11^{* * *}$ & $-.15^{* *}$ & $.47^{* * *}$ & - & & & & & & & \\
\hline 5. 5 y social problems & .03 & -.04 & $.50^{* * *}$ & $.30^{* * *}$ & - & & & & & & \\
\hline 6. $5 \mathrm{y}$ mat responsive & $-.10^{* *}$ & $.08^{*}$ & $-.32^{* * *}$ & $-.51^{* * *}$ & $-.21^{* * *}$ & - & & & & & \\
\hline 7. $10 \mathrm{y}$ internalizing & $.07^{*}$ & $-.08^{*}$ & $.45^{* * *}$ & $.39^{* * *}$ & $.37^{* * *}$ & $-.29^{* * *}$ & - & & & & \\
\hline 8. $10 \mathrm{y}$ externalizing & .04 & $-.08^{*}$ & $.31^{* * *}$ & $.58^{* * *}$ & $.22^{* * *}$ & $-.36^{* * *}$ & $.59^{* * *}$ & - & & & \\
\hline 9. 10 y social problems & .04 & -.06 & $.30^{* * *}$ & $.37^{* * *}$ & $.34^{* * *}$ & $-.24^{* * *}$ & $.45^{* * *}$ & $.43^{* * *}$ & - & & \\
\hline 10. Adol internalizing & .06 & $-.08^{*}$ & $.39^{* * *}$ & $.32^{* * *}$ & $.26^{* * *}$ & $-.21^{* * *}$ & $.47^{* * *}$ & $.37^{* * *}$ & $.36^{* * *}$ & - & \\
\hline 11. Adol externalizing & $.11^{* * *}$ & $-.09^{* *}$ & $.32^{* * *}$ & $.54^{* * *}$ & $.24^{* * *}$ & $-.36^{* * *}$ & $.40^{* * *}$ & $.56^{* * *}$ & $.34^{* * *}$ & $.59^{* * *}$ & - \\
\hline 12. Adol social problems & $.08^{*}$ & $-.11^{* * *}$ & $.32^{* * *}$ & $.38^{* * *}$ & $.25^{* * *}$ & $-.30^{* * *}$ & $.42^{* * *}$ & $.41^{* * *}$ & $.40^{* * *}$ & $.68^{* * *}$ & $.64^{* * *}$ \\
\hline
\end{tabular}

Note. $N=933$. Correlation coefficients are from the correlation matrix in Mplus with significance values. Bivariate correlations were calculated without accounting for other variables in the model. ID = iron deficiency; Mat = maternal; Adol = adolescent; $y=y e a r s ;$ $\mathrm{m}=$ months.

${ }^{*} p<.05 . ;{ }^{* *} p<.01 . ;{ }^{* * *} p<.001$.

\section{Preliminary Analyses}

All factor loadings for the latent variables were significant $(>.40, p<.001)$. The correlation matrix for the model variables is shown in Table 2. Individual tests of model paths between boys and girls revealed that there were no sex differences in the associations between severity of ID at 12-18 months and any of the age 5 behavior problems, all $p>.05$. Therefore, the analyses were conducted with both boys and girls. Maternal responsiveness at 9 months and 5 years were significantly correlated $(r=.08, p<.05)$.

\section{Model 1: Mediation Model}

The model demonstrated good fit to the data $($ CFI $>.94$, RMSEA $<.05$, SRMR $<.06)$. The path coefficients (Figure 1) indicated that more severe ID at $12-18$ months was associated with more frequent externalizing problems at age $5(\beta=.10, S E=.04$, $z=2.26, p=.02$; Table 3 ) but not with age 5 internalizing or social problems ( $p$ s $>.05$ ). There were direct associations between more severe ID at 12 18 months and adolescent externalizing $(\beta=.09$, $S E=.03, z=3.06, p=.002)$ and social problems $(\beta=.06, \quad S E=.03, z=2.34, p=.02)$, but not between severity of ID and adolescent internalizing problems, $p>.05$.

Results indicated there were five significant indirect effects between severity of ID at 12-18 months and internalizing, externalizing, and social problems in adolescence (summary of all significant pathways is shown in Table 4; indirect pathways are also outlined in Supporting Information section 3). All pathways operated through greater externalizing problems at age 5 and more negative maternal responsiveness at age 5. The variance in adolescent outcomes explained by the model variables was as follows: internalizing symptoms, $R^{2}=.28$, externalizing symptoms, $R^{2}=.34$, social problems, $R^{2}=.30$ (all $p<.001$ ).

\section{Model 2: Moderation by Maternal Responsiveness at 9 Months}

The interaction between maternal responsiveness at 9 months and severity of ID at 12-18 months predicted levels of internalizing problems at 5 years $(\beta=.29, S E=.13, z=2.22, p=.03)$. Simple slopes analyses indicated that at levels of positive maternal responsiveness ( $1 S D$ above the mean), more severe ID was associated with higher internalizing problems at 5 years, $p=.004$, but not at negative levels of maternal responsiveness ( $1 S D$ below the mean), $p=.91$. Thus, children with more severe ID and positive maternal responsiveness showed similarly high levels of internalizing problems to children with negative maternal responsiveness regardless of iron status. There were no indirect effects of the interaction on adolescent internalizing, externalizing, or social problems, $p \mathrm{~s}>.05$. The maternal responsiveness and ID in infancy interaction did not predict externalizing or social problems 
Table 3

Model 1: Estimates of Direct Pathways From Severity of ID at 1218 Months to Adolescent Internalizing, Externalizing, and Social Problems

\begin{tabular}{|c|c|c|}
\hline & $\beta$ & $95 \% \mathrm{CI}$ \\
\hline \multicolumn{3}{|l|}{ Severity of ID at $12-18$ months } \\
\hline High iron supplementation & $-.22^{* * *}$ & $-.29,-.15$ \\
\hline Low iron supplementation & $-.09^{* *}$ & $-.15,-.02$ \\
\hline Hemoglobin at 6 months & $-.12^{* * *}$ & $-.19,-.06$ \\
\hline Maternal age at birth & $-.10^{* *}$ & $-.16,-.04$ \\
\hline Received medicinal iron & $.29^{* * *}$ & $.22, .37$ \\
\hline Low SES (Graffar) & $.08^{* *}$ & $.02, .14$ \\
\hline Female sex & $-.08^{* *}$ & $-.14,-.03$ \\
\hline \multicolumn{3}{|l|}{5 y Internalizing problems } \\
\hline Severity of ID at $12-18$ months & .02 & $-.05, .10$ \\
\hline Low SES (Graffar) & $.15^{* * *}$ & $.07, .22$ \\
\hline \multicolumn{3}{|l|}{5 y externalizing problems } \\
\hline Severity of ID at $12-18$ months & $.10^{*}$ & $.01, .19$ \\
\hline Maternal stress in infancy & $.11^{*}$ & $.02, .19$ \\
\hline \multicolumn{3}{|l|}{5 y social problems } \\
\hline Severity of ID at $12-18$ months & .02 & $-.05, .10$ \\
\hline Low SES (Graffar) & $.11^{* *}$ & $.03, .18$ \\
\hline Maternal education & $-.08^{*}$ & $-.15,-.01$ \\
\hline \multicolumn{3}{|l|}{5 y maternal responsiveness } \\
\hline Severity of ID at $12-18$ months & -.05 & $-.19, .08$ \\
\hline 5 y internalizing problems & $-.16^{*}$ & $-.31,-.02$ \\
\hline 5 y externalizing problems & $-.64^{* * *}$ & $-.77,-.48$ \\
\hline 5 y social problems & $-.13 \dagger$ & $-.25, .01$ \\
\hline Maternal stress in infancy & $-.13^{* *}$ & $-.21,-.04$ \\
\hline \multicolumn{3}{|l|}{$10 \mathrm{y}$ internalizing problems } \\
\hline Severity of ID at $12-18$ months & .00 & $-.11, .09$ \\
\hline 5 y maternal responsiveness & $-.55^{* * *}$ & $-.66,-.40$ \\
\hline Maternal education & $-.09^{* *}$ & $-.15,-.04$ \\
\hline \multicolumn{3}{|l|}{10 y externalizing problems } \\
\hline Severity of ID at $12-18$ months & -.04 & $-.14, .06$ \\
\hline 5 y maternal responsiveness & $-.61^{* * *}$ & $-.69,-.48$ \\
\hline Maternal education & $-.09^{* *}$ & $-.15,-.04$ \\
\hline \multicolumn{3}{|l|}{10 y social problems } \\
\hline Severity of ID at $12-18$ months & -.01 & $-.10, .08$ \\
\hline 5 y maternal responsiveness & $-.47^{* * *}$ & $-.56,-.34$ \\
\hline Female sex & $.12^{* * *}$ & $.06, .17$ \\
\hline \multicolumn{3}{|l|}{ Adolescent internalizing problems } \\
\hline Severity of ID at $12-18$ months & .03 & $-.03, .08$ \\
\hline $10 \mathrm{y}$ internalizing problems & $.36^{* * *}$ & $.27, .44$ \\
\hline 10 y externalizing problems & $.08 \dagger$ & $-.004, .16$ \\
\hline 10 y social problems & $.15^{* * *}$ & $.09, .22$ \\
\hline Female & $.07^{*}$ & $.01, .12$ \\
\hline Maternal education & $-.11^{* * *}$ & $-.16,-.05$ \\
\hline \multicolumn{3}{|l|}{ Adolescent externalizing problems } \\
\hline Severity of ID at $12-18$ months & $.09^{* *}$ & $.03, .14$ \\
\hline $10 \mathrm{y}$ internalizing problems & $.09^{*}$ & $.003, .17$ \\
\hline 10 y externalizing problems & $.45^{* * *}$ & $.37, .53$ \\
\hline 10 y social problems & $.09^{* *}$ & $.03, .16$ \\
\hline Female & $.06^{*}$ & $.01, .11$ \\
\hline Maternal education & $-.07^{*}$ & $-.13,-.02$ \\
\hline
\end{tabular}

$+$

Continued

\begin{tabular}{llc}
\hline & $\beta$ & $95 \%$ CI \\
\hline Adolescent social problems & & \\
$\quad$ Severity of ID at 12-18 months & $.06^{*}$ & $.01, .12$ \\
10 y internalizing problems & $.24^{* * *}$ & $.16, .31$ \\
10 y externalizing problems & $.18^{* * *}$ & $.10, .25$ \\
10 y social problems & $.20^{* * *}$ & $.13, .27$ \\
Female & $.15^{* * *}$ & $.09, .20$ \\
Maternal education & $-.07^{*}$ & $-.12,-.01$ \\
Formula/milk intake (average ml/day) & $-.05^{*}$ & $-.09,-.004$ \\
\hline
\end{tabular}

Note. All estimates reported are standardized estimates and $95 \%$ confidence intervals (CI) for each of the direct pathways to behavior problems. Dependent variables are in bold with independent variables and associated standardized $(\beta)$ coefficients. Covariates were included in the final model if they were associated with the model variable at $p<.05$. $\mathrm{y}=$ years; SES $=$ socioeconomic status; ID = iron deficiency.

$\dagger p<.10 .{ }^{*} p<.05 .{ }^{* *} p<.01 . ;{ }^{* * *} p<.001$.

at 5 years, $p$ s $>.05$ (Table S3). Follow-up analyses (found in Supporting Information section 5.2) suggest that the threshold for ID in the interaction with maternal responsiveness at 9 months predicting 5year internalizing problems was IDA (interaction shown in Figure 2). Children with IDA and positive maternal responsiveness showed similarly high levels of internalizing problems to children with negative maternal responsiveness regardless of iron status. Children who did not have IDA at 12 18 months with positive maternal responsiveness at 9 months had the lowest levels of internalizing problems at 5 years.

\section{Model 3: Moderation by Maternal Responsiveness at 5 Years}

The interaction between maternal responsiveness at 5 years and severity of ID at 12-18 months was not significantly related to 5-year internalizing, externalizing, or social problems, all $p s>.05$ (Table S4).

\section{Discussion}

This study identified several direct and indirect pathways between severity of ID at 12-18 months and higher levels of adolescent internalizing, externalizing, and social problems as reported by parents. Our findings indicate that effects from more severe ID at 12-18 months to social, emotional, and behavioral problems in adolescence operated through age 5 externalizing behaviors and negative 
Mediation model: ID severity

ID severity $\rightarrow 5$ y Externalizing $\rightarrow 5$ y Maternal responsiveness $\rightarrow 10$ y Internalizing $\rightarrow$ Adolescent internalizing

$.012^{*} \quad .002, .025$

ID severity $\rightarrow 5$ y Externalizing $\rightarrow 5$ y Maternal responsiveness $\rightarrow 10$ y social $\rightarrow$ Adolescent internalizing

ID severity $\rightarrow 5$ y Externalizing $\rightarrow 5$ y Maternal responsiveness $\rightarrow 10$ y Externalizing $\rightarrow$ Adolescent externalizing

$.017^{*}$

$.001, .010$

ID severity $\rightarrow 5$ y Externalizing $\rightarrow 5$ y Maternal responsiveness $\rightarrow 10$ y Internalizing $\rightarrow$ Adolescent social

$.008^{*}$

ID severity $\rightarrow 5$ y Externalizing $\rightarrow 5$ y Maternal responsiveness $\rightarrow 10$ y Social $\rightarrow$ Adolescent social

$.006^{*}$

$.002, .034$

ID severity $\rightarrow 5$ y Externalizing $\rightarrow 5$ y Maternal responsiveness $\rightarrow 10$ y Externalizing $\rightarrow$ Adolescent social

$.007^{*}$

Note. All estimates are standardized estimates and 95\% confidence intervals (CIs) for each of the indirect pathways in the model. ID = iron deficiency; IDA = ID anemia; $y=$ years.

$\dagger p<.10 . ;{ }^{*} p<.05$.

maternal responsiveness. Our finding that externalizing behaviors at 5 years followed more severe ID in infancy, which was then associated with more negative maternal responsiveness, adds to the existing literature by specifying a previously unrecognized pathway by which early life ID may impact children's emotional and behavioral adjustment across development. This new externalizing pathway may be apparent in individuals with less chronic or severe postnatal ID (discussed below).

The severity of ID at $12-18$ months predicted several indirect pathways to adolescent internalizing, externalizing, and social problems. Further analyses indicated that the threshold for these pathways was ID without anemia (Supporting Information section 5.2). Thus, even less severe forms of ID may have a negative impact on development, with increasing problems associated with greater severity of ID. This is particularly important since ID without anemia is not routinely monitored or treated but may still have lasting impacts on neurobehavioral development.

Interestingly, all five significant model pathways relating to severity of ID at 12-18 months to greater age 5 externalizing symptoms were associated with more negative maternal responsiveness at 5 years.

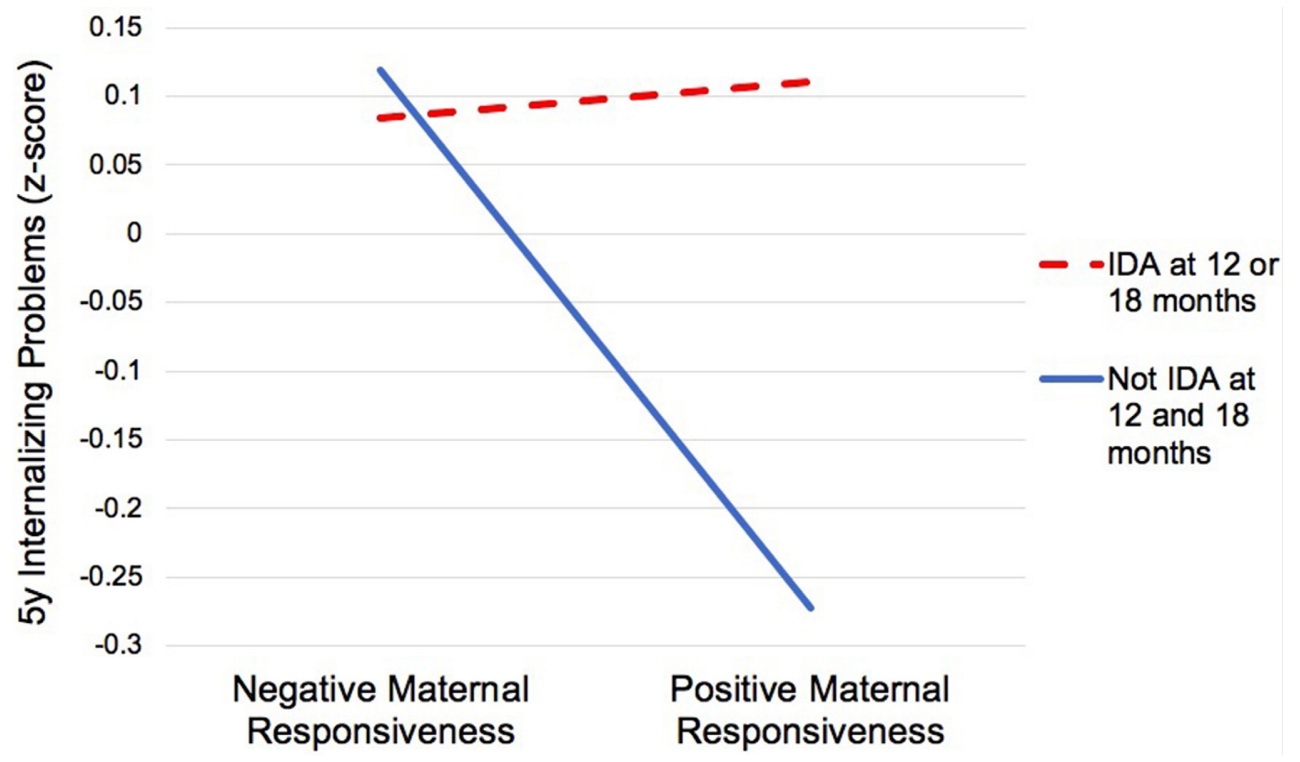

Figure 2. Simple slopes of the interaction between maternal responsiveness at 9 months and iron deficiency anemia (IDA) at 1218 months on 5y internalizing problems for Model 2 (severity of ID) and Model 5 (threshold of ID: see Supporting Information section 5.2). Positive maternal responsiveness is one standard deviation above the mean, and negative maternal responsiveness is one standard deviation below the mean. Higher values on the $y$-axis indicate higher child internalizing problems. 
Negative maternal responsiveness at age 5 was related to children's internalizing, externalizing, and social problems at age 10, which remained stable into adolescence. These findings are particularly interesting given that the 5-year behavioral disruption following ID in infancy was centered in children's externalizing behaviors, that is, their antisocial, oppositional, and hostile behaviors. Externalizing behaviors could set the stage for subsequent adjustment problems if mothers have more negative responses to children with these problematic behaviors. In contrast, findings from the other major long-term study of ID in infancy, the Costa Rica study mentioned above, emphasized internalizing problems (Lozoff et al., 1998). One potential explanation for this difference is that the Costa Rica study involved children whose ID was not identified and treated until the second year of life, termed "chronic ID" (Lozoff et al., 2000, 2013). In this study, IDA was identified at 6, 12, and 18 months and promptly treated. Consequently, ID as assessed in this study was typically less chronic than in the Costa Rica study. Differences in severity and chronicity of ID between samples could lead to different phenotypes observed. In addition, the infants in this study were a more psychosocially at-risk population than in Costa Rica, partially due to the military dictatorship that was present from 1973 to 1990, just before the target children were born. The co-occurrence of psychosocial risk could have contributed to a different phenotype in infants with ID. In addition, negative maternal responsiveness is not a phenomenon specific to ID as there is evidence that maternal responsiveness partially mediates associations between early cumulative psychosocial, physical, and sociodemographic risk and adolescent externalizing problems (Doan, Fuller-Rowell, \& Evans, 2012). Future studies should evaluate whether earlier maternal responsiveness following ID in infancy and early childhood may be a more proximal social mediator of the effects of ID on children's subsequent development than disruptions in child behavior.

This study found that the single significant indirect pathway from ID at $12-18$ months to externalizing behaviors in adolescence involved externalizing behaviors (but not internalizing or social problems) at 5 and 10 years. It is possible that neurobiological disruptions due to ID in infancy and early childhood (Beard \& Connor, 2003; Lozoff, 2011; Unger et al., 2007) may have contributed to increased externalizing problems at age 5, which then influenced maternal responsiveness through psychosocial mechanisms. Thus, our results suggest both neurobiological and psychosocial mechanisms leading to externalizing problems following ID at 12-18 months. The current findings are distinct from the functional isolation hypothesis, which suggests that infants and young children with ID are more socially wary and seek out fewer interactions with caregivers, who then provide less developmentally supportive interactions by engaging less with their children. Based on the hypothesis, these children receive less stimulation and positive interactions over time, contributing to behavior problems later in life. In the current analyses, ID in infancy contributed to more externalizing behaviors at 5 years, which may then elicit more negative maternal behaviors such as negative affect and fewer positive social interactions. There is also an alternate possibility that child ID at 12 18 months could directly affect maternal responsiveness, which would then influence later child behavior problems. However, our preliminary analyses (see Supporting Information section 6) and past research (East et al., 2017; Lozoff et al., 2008, 1998) suggests that child behavior problems following early ID are more likely to precede alterations in maternal responsiveness. Future research is needed to test this directionality more directly, as early as infancy. Differences in the chronicity and severity of ID in infancy and early childhood between this cohort and previous cohorts could result in a different phenotype than the more socially wary, disengaged infants suffering from more chronic and severe ID, as in the Costa Rica study. This externalizing behavior and parenting pathway has not been previously described and may be an important mechanism by which less chronic or severe ID influences behavior into adolescence.

The results indicate that there are direct associations between the severity of ID at 12-18 months and greater externalizing and social problems in adolescence, above and beyond indirect effects. Thus, there may be additional pathways, such as neurobiological alterations and neurocognitive difficulties that are contributing to the adolescent outcomes. Thus far, ID in early life has been associated with disruptions in glial and neuronal development, neurometabolism, epigenetic regulation, myelination, and function of neurotransmitters (Beard \& Connor, 2003; Georgieff, 2011; Lozoff, 2011; Lozoff, Beard, et al., 2006; Unger et al., 2007). In addition, more research in humans is needed to understand the neurocognitive alterations and other social and emotional factors that could be altered by early postnatal ID. Lasting neurocognitive alterations related to effects on neurotransmitter systems and myelination, for example, could exert unique 
influences on adolescent behavior that do not operate through changes in behavior at previous time points. In fact, developmental changes in the brain across adolescence could make earlier vulnerabilities such as ID in infancy and early childhood more potent, producing an emergence of new behavior problems (Dahl, 2004).

It was puzzling that ID at $12-18$ months predicted both 5-year and adolescent externalizing symptoms but not 10 -year symptoms in this study. Externalizing problems at 5 years is closer in time to ID, possibly explaining the larger associations. Adolescence is a developmental period when the emergence of greater externalizing problems might lead to more parent report of problems. It is also possible that a change in measurement could have led to the unexpected lack of direct association at 10 years. The CBCL version at 10 years only had two scales that matched externalizing problems at other years, and thus, we did not create a latent variable like we did with the three scales of externalizing problems at 5 years and adolescence.

Our moderation analyses revealed that maternal responsiveness in infancy moderated the association between IDA at $12-18$ months and internalizing problems at 5 years. These results suggest that 5 year-olds who had IDA at 12 or 18 months may not experience the buffering effects of positive maternal responsiveness in infancy on internalizing problems. IDA at 12-18 months could make infants less able to benefit from positive environmental inputs. Age 5 maternal responsiveness did not moderate the association between ID at 12-18 months and age 5 behavior problems. This finding could be due to the timing of assessment (i.e., 5 years), as this point may be beyond an optimal period for this moderation, or it could be due to a difference in measurement (observer-report vs. interview of mother). Programs implementing parenting interventions should be aware of the role that ID may play in influencing the effectiveness of interventions to reduce later internalizing symptoms.

The study's findings provide insight into the specific paths of child and maternal behavior by which ID at $12-18$ months affects later child functioning, pointing to potential intervention targets, including preventing early externalizing behaviors and improving maternal responsiveness following early ID. However, it remains unclear whether such early interventions would have lasting impacts into adolescence as the effect sizes in this study are small, which is not surprising given that these are distal outcomes unfolding over 14-15 years. Nonetheless, these findings add to the literature by: (a) identifying previously undescribed pathways involving early externalizing problems and negative maternal responsiveness by which ID impacts adolescent behavior; (b) suggesting that preventing ID with or without anemia in infants and young children could help prevent adolescent social, emotional, and behavior problems; (c) identifying targets for child and family behavioral interventions for children with ID in infancy and early childhood; and (d) observing that positive maternal responsiveness in infancy may not buffer infants and young children with IDA from developing later behavior problems. This study suggests that less optimal parent-child interactions following early ID may be a mediator for behavior problems, similar to individuals in other risk conditions. For instance, there is some evidence that altered maternal responsiveness is a mediator between cumulative psychosocial risk and behavior problems (Doan et al., 2012), suggesting that there may be shared mechanisms between early risk conditions. As the contribution of ID to behavior is not always considered by researchers and practitioners working with at-risk families, this finding is particularly important.

It is important to note this study's limitations when interpreting its findings. Children's socioemotional and behavioral outcomes were parentreported on the CABI at age 5 and the CBCL at 10 years and in adolescence. However, the correlations between similar areas of functioning were substantial (e.g., between internalizing problems at 5 years, 10 years, and adolescence), indicating that they indexed the same underlying construct. Similarly, parents reported their child's symptomology at 5 years, 10 years, and adolescence, and their own parenting behavior at 5 years. The significant correlations between symptomology and parenting are likely due in part to having the same reporter, which should be considered. In addition, 5-year behaviors and maternal responsiveness were collected at the same time point, which makes model interpretation more difficult. Additionally, due to limited funding, some participants were not assessed at age 5. We have attempted to account for this using advanced techniques for handling missing data in our model. Another limitation is that data were not collected on paternal responsiveness; we believe that paternal behaviors may be very important. This is an important area for future work. The observed lack of associations of ID at 12-18 months with later internalizing problems may relate to our use of parent report, given that parents may be better able to identify externalizing problems than internalizing problems. We did not 
rely on self-report of behavior problems in adolescence, because we wanted to keep the reporter of behavior problems consistent across measurement. However, there is evidence of convergent associations of ID on parent- and adolescent-reported behaviors (Doom et al., 2018). Future research should investigate pathways from ID in infancy and early childhood to self-reported behavior problems in adolescence. We adjusted for a number of child- and family-level factors that could contribute to differences, but it is possible that unmeasured variables could have contributed to variation in the analyses. Children from low SES backgrounds are more likely to have ID and other nutritional deficiencies in addition to increased rates of social, emotional, and behavioral problems. SES and related family and environmental factors were statistically controlled in these analyses, but a consideration of children's context is important. Another limitation is that fetal-neonatal ID was not assessed, and co-occurring micronutrient deficiencies could have contributed to the findings. The sample consisted of healthy infants born at term who had access to health care, no generalized undernutrition, and literate parents. Thus, the findings may not generalize to other populations. Finally, although the analyses included covariate control, a causal connection cannot be inferred.

Despite these limitations, the results from this large cohort of Chilean adolescents revealed important findings, namely that more severe ID at 12 18 months was associated with problematic adjustment at adolescence by way of child externalizing problems and negative maternal responsiveness in early childhood. These findings shed light on mechanisms involving changes in neurobehavioral development and parenting behaviors following ID in infancy and early childhood. Although replication is needed, these findings suggest that more severe ID at 12-18 months may contribute to internalizing, externalizing, and social problems in adolescence through early alterations in both child externalizing behaviors and maternal responsiveness. The pathway between children's externalizing behavior and mothers' responsiveness has not been previously described and may be an important target for interventions for those who were iron deficient as infants or young children to reduce adolescent behavior problems. The contribution of ID to emotion and behavior is rarely considered by researchers or practitioners who work with at-risk families. The current findings indicate that greater attention should be paid to children's iron status as a potential etiological marker of children's externalizing problems. The results also suggest that ID even without anemia may have a negative impact on neurodevelopment. These findings are particularly important, since ID without anemia is not routinely monitored or treated in the United States or internationally. Increasing attention should be given to preventing ID with and without anemia. Findings also indicate that positive maternal responsiveness did not offset the influence of early IDA on internalizing problems at 5 years. This finding may illuminate why some children show fewer effects of positive parenting in terms of their emotional and behavioral functioning, as IDA could make infants and young children less able to benefit from positive environmental inputs. Iron status could be an important predictor of responses to early interventions. This possibility should be explored in future research.

\section{References}

Achenbach, T., \& Edelbrock, C. (1991). Manual for the Child Behavior Checklist/4-18 and revised child behavior profile. Burlington, VT: University of Vermont.

Achenbach, T., \& Rescorla, L. (2001). Manual for the ASEBA school-age forms and profiles. Burlington, VT: University of Vermont.

Alvarez, M., Muzzo, S., \& Ivanovic, D. (1985). Scale for the measurement of the socioeconomic level in the area of health. Revista Medica de Chile, 113, 243-249.

Beard, J. L., \& Connor, J. R. (2003). Iron status and neural functioning. Annual Review of Nutrition, 23, 41-58. https://doi.org/10.1146/annurev.nutr.23.020102.075739

Bradley, R. H., Corwyn, R. F., \& Whiteside-Mansell, L. (1996). Life at home: Same time, different places-An examination of the HOME inventory in different cultures. Infant and Child Development, 5, 251-269. https://doi.org/10.1002/(SICI)1099-0917(199612)5: 4<251::AID-EDP137>3.0.CO;2-I

Caldwell, B. M., \& Bradley, R. H. (1984). Home observation for measurement of the environment (Rev. ed.). Little Rock, AR: University of Arkansas.

Cook, J. D., \& Finch, C. A.( 1979). Assessing iron status of a population. American Journal of Clinical Nutrition, 32, 2115 - 2119. https://doi.org/10.1093/ajcn/32.10.2115

Cowan, P. A., \& Cowan, C. P. (1990). Becoming a family: Research and intervention. Methods of Family Research: Biographies of Research Projects, 1, 1-51.

Dahl, R. E. (2004). Adolescent brain development: A period of vulnerabilities and opportunities. Keynote address. Annals of the New York Academy of Sciences, 1021, 1-22.

Doan, S. N., Fuller-Rowell, T. E., \& Evans, G. W. (2012). Cumulative risk and adolescent's internalizing and externalizing problems: The mediating roles of maternal responsiveness and self-regulation. Developmental Psychology, 48, 1529.https://doi.org/10.1037/a0027815 
Doom, J. R., \& Georgieff, M. K. (2014). Striking while the iron is hot: Understanding the biological and neurodevelopmental effects of iron deficiency to optimize intervention in early childhood. Current Pediatrics Reports, 2, 291-298. https:/ / doi.org/10.1007/s40124-014-0058-4

Doom, J. R., Richards, B., Caballero, G., Delva, J., Gahagan, S., \& Lozoff, B.( 2018). Infant iron deficiency and iron supplementation predict adolescent internalizing, externalizing, and social problems. Journal of Pediatrics, 195, 199-205. e2. https://doi.org/10.1016/j.jpeds.2017. 12.008

East, P., Lozoff, B., Delker, E., Blanco, E., Encina, P., \& Gahagan, S. (2017). Infant iron deficiency, child affect, and maternal unresponsiveness: Testing the long-term effects of functional isolation. Developmental Psychology, 53, 2233-2244. https:/ / doi.org/10.1037/dev0000385

Georgieff, M. K. (2011). Long-term brain and behavioral consequences of early iron deficiency. Nutrition Reviews, 69, S43-S48. https://doi.org/10.1111/j.1753-4887.2011. 00432.x

Han, W.-J., Leventhal, T., \& Linver, M. R. (2004). The home observation for measurement of the environment (home) in middle childhood: A study of three largescale data sets. Parenting, 4, 189-210. https://doi.org/ 10.1207/s15327922par0402\&3_5

Hensch, T. K. (2004). Critical period regulation. Annual Review of Neuroscience, 27, 549-579. https://doi.org/10. 1002/chin. 200446297

Holmes, T. H., \& Rahe, R. H. (1967). The Social Readjustment Rating Scale. Journal of Psychosomatic Research, 11, 213-218. https:/ / doi.org/10.1016/0022-3999(67)90010-4

Hu, L., \& Bentler, P. M. (1999). Cutoff criteria for fit indexes in covariance structure analysis: Conventional criteria versus new alternatives. Structural Equation Modeling: A Multidisciplinary Journal, 6, 1-55. https://d oi.org/10.1080/10705519909540118

Kassebaum, N. J., Jasrasaria, R., Naghavi, M., Wulf, S. K., Johns, N., Lozano, R., . . . Eisele, T. P. (2014). A systematic analysis of global anemia burden from 1990 to 2010. Blood, 123, 615-624. https://doi.org/10.1182/ blood-2013-06-508325

Katz, L. F., \& Gottman, J. M. (1993). Patterns of marital conflict predict children's internalizing and externalizing behaviors. Developmental Psychology, 29, 940. https: / / doi.org/10.1037/ / 0012-1649.29.6.940

Kline, R. B. (2015). Principles and practice of structural equation modeling. New York, NY: Guilford.

Little, T. D. (2013). Longitudinal structural equation modeling. New York, NY: Guilford.

Little, T. D., Lindenberger, U., \& Nesselroade, J. R. (1999). On selecting indicators for multivariate measurement and modeling with latent variables: When "good" indicators are bad and "bad" indicators are good. Psychological Methods, 4, 192-211. https://doi.org/10.1037/ 1082-989X.4.2.192

Lozoff, B. (2011). Early iron deficiency has brain and behavior effects consistent with dopaminergic dysfunction. Journal of Nutrition, 141, 740S-746S. https:/ / doi.org/10.3945/jn.110.131169

Lozoff, B., Beard, J., Connor, J., Felt, B., Georgieff, M., \& Schallert, T. (2006). Long-lasting neural and behavioral effects of iron deficiency in infancy. Nutrition Reviews, 64, S34-S43. https://doi.org/10.1111/j.1753-4887.2006. tb00243.x

Lozoff, B., Brittenham, G. M., Wolf, A. W., McClish, D. K., Kuhnert, P. M., Jimenez, E., . . Krauskoph, D. (1987). Iron deficiency anemia and iron therapy effects on infant developmental test performance. Pediatrics, 79, 981-995.

Lozoff, B., Castillo, M., Clark, K. M., Smith, J. B., \& Sturza, J. (2014). Iron supplementation in infancy contributes to more adaptive behavior in 10-year-old children. Journal of Nutrition, 144, 838-845. https://doi. org/10.3945/jn.113.182048

Lozoff, B., Clark, K. M., Jing, Y., Armony-Sivan, R., Angelilli, M. L., \& Jacobson, S. W. (2008). Dose-response relationships between iron deficiency with or without anemia and infant social-emotional behavior. Journal of Pediatrics, 152, 696-702. https://doi.org/10. 1016/j.jpeds.2007.09.048

Lozoff, B., De Andraca, I., Castillo, M., Smith, J., Walter, T., \& Pino, P. (2003). Behavioral and developmental effects of preventing iron-deficiency anemia in healthy full-term infants. Pediatrics, 112, 846-854.

Lozoff, B., Jimenez, E., Hagen, J., Mollen, E., \& Wolf, A. W. (2000). Poorer behavioral and developmental outcome more than 10 years after treatment for iron deficiency in infancy. Pediatrics, 105, E51-E51. https://doi. org/10.1542/peds.105.4.e51

Lozoff, B., Kaciroti, N., \& Walter, T.( 2006). Iron deficiency in infancy: Applying a physiologic framework for prediction. American Journal of Clinical Nutrition, 84, 1412-1421. https://doi.org/10.1093/ajcn/84.6.1412

Lozoff, B., Klein, N. K., Nelson, E. C., McClish, D. K., Manuel, M., \& Chacon, M. E. (1998). Behavior of infants with iron deficiency anemia. Child Development, 69, 24-36. https://doi.org/10.2307/1132067

Lozoff, B., Smith, J. B., Kaciroti, N., Clark, K. M., Guevara, S., \& Jimenez, E. (2013). Functional significance of early-life iron deficiency: Outcomes at 25 years. Journal of Pediatrics, 163, 1260-1266. https://doi.org/10.1016/j. jpeds.2013.05.015

Lukowski, A. F., Koss, M., Burden, M. J., Jonides, J., Nelson, C. A., Kaciroti, N., . . . Lozoff, B. (2010). Iron deficiency in infancy and neurocognitive functioning at 19 years: Evidence of long-term deficits in executive function and recognition memory. Nutritional Neuroscience, 13, 54-70. https://doi.org/10.1179/ 147683010X12611460763689

Maslowsky, J., Jager, J., \& Hemken, D. (2015). Estimating and interpreting latent variable interactions: A tutorial for applying the latent moderated structural equations method. International Journal of Behavioral Development, 39, 87-96. https://doi.org/10.1177/0165025414552301 
Mattanah, J. F. (2001). Parental psychological autonomy and children's academic competence and behavioral adjustment in late childhood: More than just limit-setting and warmth. Merrill-Palmer Quarterly, 47, 355-376. https: / / doi.org/10.1353/mpq.2001.0017

Miller, N. (1987). Scales and factors of the Child Adaptive Behavior Inventory. Unpublished manuscript, Becoming a Family Project, University of California at Berkeley.

Mills-Koonce, W. R., Willoughby, M. T., Garrett-Peters, P., Wagner, N., Vernon-Feagans, L., \& Investigators, F. L. P. K. (2016). The interplay among socioeconomic status, household chaos, and parenting in the prediction of child conduct problems and callous-unemotional behaviors. Development and Psychopathology, 28, 757771. https: / /doi.org/10.1017/S0954579416000298

Moeller, J. (2015). A word on standardization in longitudinal studies: Don't. Frontiers in Psychology, 6, 1389. https://doi.org/10.3389/fpsyg.2015.01389

Muthén, B. (2011). Applications of causally defined direct and indirect effects in mediation analysis using SEM in Mplus. Technical report (pp. 1-110). Retrieved from https:// www.statmodel.com

Muthén, L., \& Muthén, B. (2010). Mplus user's guide (6th ed.). Los Angeles, CA: Author.

Muthén, L. K., \& Muthén, B. O. (2012). Mplus version 7 user's guide. Los Angeles, CA: Author.

Newman, D. A. (2003). Longitudinal modeling with randomly and systematically missing data: A simulation of ad hoc, maximum likelihood, and multiple imputation techniques. Organizational Research Methods, 6, 328-362. https:/ / doi.org/10.1177/1094428103254673

Oski, F. A. (1993). Iron deficiency in infancy and childhood. New England Journal of Medicine, 329, 190-193. https:/ / doi.org/10.1056/NEJM199307153290308

Raghunathan, T., Solenberger, P., \& van Hoewyk, J. (2000). IVEWARE: Imputation and variance estimation software: Installation instructions and user guide. Ann Arbor, MI: Survey Research Center, Institute of Social Research, University of Michigan.

Roncagliolo, M., Garrido, M., Walter, T., Peirano, P., \& Lozoff, B.( 1998). Evidence of altered central nervous system development in infants with iron deficiency anemia at 6 mo: Delayed maturation of auditory brainstem responses. American Journal of Clinical Nutrition, 68, 683-690. https://doi.org/10.1093/ajcn/68.3.683

Rubin, D. B. (1987). Multiple imputation for nonresponse in surveys. New York, NY: Wiley.

Rubio-Stipec, M., Bird, H., Canino, G., \& Gould, M. (1990). The internal consistency and concurrent validity of a Spanish translation of the Child Behavior Checklist. Journal of Abnormal Child Psychology, 18, 393-406. https: / / doi.org/10.1007/bf00917642

Siddappa, A. M., Georgieff, M. K., Wewerka, S., Worwa, C., Nelson, C. A., \& Deregnier, R.-A. (2004). Iron deficiency alters auditory recognition memory in newborn infants of diabetic mothers. Pediatric Research, 55, 1034. https:/ / doi.org/10.1203/01.pdr.0000127021.38207.62
Sulik, M. J., Blair, C., Mills-Koonce, R., Berry, D., Greenberg, M., Investigators, F. L. P., . . . Garrett-Peters, P. T. (2015). Early parenting and the development of externalizing behavior problems: Longitudinal mediation through children's executive function. Child Development, 86, 1588-1603. https:/ / doi.org/10.1111/cdev.12386

Unger, E. L., Paul, T., Murray-Kolb, L. E., Felt, B., Jones, B. C., \& Beard, J. L.( 2007). Early iron deficiency alters sensorimotor development and brain monoamines in rats. Journal of Nutrition, 137, 118-124. https://doi.org/ 10.1093/jn/137.1.118

Walter, T., Pino, P., Pizarro, F., \& Lozoff, B. (1998). Prevention of iron-deficiency anemia: Comparison of high-and low-iron formulas in term healthy infants after six months of life. The Journal of Pediatrics, 132, 635-640. https: / /doi.org/10.1016/S0022-3476(98)70352-X

\section{Supporting Information}

Additional supporting information may be found in the online version of this article at the publisher's website:

Figure S1. Flow Chart of Study Participants

Figure S2. Hypothesized Model of Effects Stemming From Poorer Iron Status in Infancy to Subsequent Internalizing, Externalizing, and Social Problems (Model 1)

Figure S3. Hypothesized Model of Effects Stemming From Poorer Iron Status in Infancy to Subsequent Internalizing, Externalizing, and Social Problems, Including the Interaction Between Iron Status in Infancy and Maternal Responsiveness at Infancy and 5 Years (Tested in Separate Models: Models 2 and 3)

Figure S4. Model 4a Results (Comparing the 3 Iron Status Groups: Iron Deficiency Anemia, Iron Deficiency Without Anemia, and Iron Sufficiency) Showing Standardized Estimates ( $\beta$ )

Figure S5. Model 4b Results (Iron Deficiency With or Without Anemia vs. Iron Sufficiency) Showing Standardized Estimates $(\beta)$

Table S1. Iron Status Ns at 12 and 18 Months

Table S2. Descriptive Statistics by Iron Deficiency Group

Table S3. Estimates of Direct Pathways From Severity of Iron Deficiency at 12-18 Months to Adolescent Socioemotional Problems With Maternal Responsiveness in Infancy as a Moderator (Model 2)

Table S4. Estimates of Direct Pathways From Severity of Iron Deficiency at 12-18 Months to Adolescent Socioemotional Problems With Maternal Responsiveness at 5 Years as a Moderator (Model 3) 
Table S5. Estimates of Direct Pathways From Iron Deficiency With and Without Anemia (Dummy-Coded) at 12-18 Months to Adolescent Socioemotional Problems (Model 4a; Iron Deficiency Anemia vs. Iron Deficiency Without Anemia vs. Iron Sufficiency)

Table S6. Estimates of Direct Pathways From Iron Deficiency With or Without Anemia at 1218 Months to Adolescent Socioemotional Problems (Model 4b; Iron Deficiency With and Without Anemia vs. Iron Sufficiency)

Table S7. Summary of Significant Indirect Pathways Between Iron Deficiency at 12-18 Months and Adolescent Socioemotional Problems (Models 4 and 5)
Table S8. Estimates of Direct Pathways From Iron Deficiency With and Without Anemia (Dummy-Coded) at 12-18 Months to Adolescent Socioemotional Problems With Maternal Responsiveness at 9 Months as a Moderator (Model 5; Iron Deficiency Anemia vs. Iron Deficiency Without Anemia vs. Iron Sufficiency)

Table S9. Estimates of Direct Pathways From Iron Deficiency With and Without Anemia (Dummy-Coded) at 12-18 Months to Adolescent Socioemotional Problems With Maternal Responsiveness at 5 Years as a Moderator (Model 6; Iron Deficiency Anemia vs. Iron Deficiency Without Anemia vs. Iron Sufficiency)

Appendix S1. Supplemental Analyses 